\title{
Concentração inibitória mínima (CIM) de oito antimicrobianos frente isolados de Streptococcus suis
}

Felipe Masiero SALVARANI ${ }^{1}$

Flávia Ferreira PINTO ${ }^{1}$

Francisco Carlos Faria LOBATO $^{1}$

Ronnie Antunes de ASSIS 2

Luciana Aramuni

GONÇALVES ${ }^{1}$

Nelson Éder MARTINS ${ }^{1}$

Inácio José CLEMENTINO ${ }^{3}$

Adrienny Trindade Reis

COSTA $^{4}$

\section{Correspondência para:}

Francisco Carlos Faria Lobato

Departamento de Medicina Veterinária

Preventiva, Laboratório de Doenças

Bacterianas, EV-UFMG - Cx. Postal 567, Av. Antônio Carlos, 6627, CEP 30123-970,

Belo Horizonte-MG

E-mail: flobato@vet.ufmg.br

Recebido para publicação: 30/08/2005 Aprovado para publicação: 20/09/2007

\author{
1 - Escola de Veterinária da Universidade Federal de Minas Gerais, Belo \\ Horizonte - MG \\ 2 - Laboratório Nacional Agropecuário de Minas Gerais (LANAGRO/MG) \\ 3 - Universidade Federal da Paraíba, Patos - PB \\ 4 - Instituto de Pesquisas Veterinárias Especializadas, Belo Horizonte - MG
}

\author{
Palavras-chave: \\ Streptococcus suis. \\ Testes de sensibilidade microbiana. \\ Antibióticos. \\ Suínos.
}

Avaliou-se a concentração inibitória mínima (CIM) de 75 isolados de Streptococcus suis frente a oito antimicrobianos freqüentemente utilizados no controle da infecção por esse microrganismo. A CIM foi realizada em placas previamente preparadas com ágar sangue, contendo concentrações variando de 0,25 a $256 \mu \mathrm{g} / \mathrm{ml}$ dos seguintes antimicrobianos: amoxicilina, ampicilina, penicilina, ceftiofur sódico, florfenicol, lincomicina, penicilina, sulfametoxazol-trimetoprim e tetraciclina. A amoxicilina nas concentrações de 1 e $2 \mu \mathrm{g} / \mathrm{ml}$, o florfenicol a $1 \mu \mathrm{g} / \mathrm{ml}$ e o sulfametoxazol-trimetoprim nas concentrações de 2 e 8 $\mu \mathrm{g} / \mathrm{ml}$, foram os antimicrobianos frente aos quais os microrganismos apresentaram menor resistência. Em contraste, a ampicilina, tetraciclina, ceftiofur sódico e lincomicina, foram menos efetivos, apresentando CIM de (64 e $128 \mu \mathrm{g} / \mathrm{ml}),(64$ e $128 \mu \mathrm{g} / \mathrm{ml}),(128$ e $256 \mu \mathrm{g} / \mathrm{ml})$ e $(>256 \mu \mathrm{g} / \mathrm{ml})$, respectivamente. Os resultados deste estudo demonstram que a amoxicilina e o florfenicol são os antibióticos de escolha para o tratamento de infecções pelo $S$. suis em suínos.

\section{Introdução}

Infecções provocadas pelo Streptococcus suis estão distribuídas na maioria dos países com produção intensiva de suínos, sendo considerado um dos principais problemas na suinocultura mundial. ${ }^{1} \mathrm{O}$ agente é responsável por quadros de meningite, artrite, septicemia, endocardite, poliserosite, broncopneumonia e aborto em suínos. ${ }^{2}$ A meningite em suínos é o mais importante sinal clínico observado e acomete principalmente animais confinados, criados em altas densidades. Porém, a introdução de animais contaminados nos plantéis, também pode levar ao aparecimento da doença em suínos recém desmamados ou em fase de crescimento. ${ }^{3}$ Taxas de mortalidade mais altas ocorrem geralmente em rebanhos de terminação que compram e alojam leitões de diferentes origens e em rebanhos infectados pela primeira vez. ${ }^{4}$

Infecções associadas à presença de $S$. suis são identificadas em várias espécies animais, tais como: ruminantes, eqüinos, aves e homem. Atualmente, o agente pode ser considerado um dos mais importantes microrganismos zoonóticos, provocando quadros de meningite, endocardite e septicemia no homem. ${ }^{5}$ Perdas econômicas para a indústria suína causadas pela presença do agente estão estimadas em mais de 300 milhões de dólares nos Estados Unidos. ${ }^{6}$ Fatores como estresse térmico, lotação excessiva e doenças concorrentes como a síndrome reprodutiva e respiratória dos suínos, pseudoraiva e infecções bacterianas contribuem para a manifestação da doença. ${ }^{1}$

Streptococcus suis possui trinta e cinco diferentes sorotipos (1 a 34 1/2), classificados de acordo com a presença de antígenos capsulares, sendo o sorotipo 2 o mais 
comumente isolado ${ }^{7}$ e associado com os principais sinais clínicos nos suínos em todo o mundo. ${ }^{6}$

Vários procedimentos têm sido implementados visando à eliminação de $S$. suis das granjas, porém nenhum deles apresentou resultados satisfatórios. A utilização de vacinas autógenas como método de prevenção da infecção apresenta uma proteção incompleta ${ }^{1}$, justificando assim o uso intensivo de antimicrobianos para o controle da infecção. As principais drogas utilizadas para o tratamento e prevenção da doença são as penicilinas, ampicilina, amoxicilina, cefalosporinas, florfenicol, quinolonas e uma combinação de sulfa e trimetoprim. ${ }^{4}$ Entretanto, resistência bacteriana a diferentes antimicrobianos tem sido descrita em diversos trabalhos. ${ }^{8,9} \mathrm{Uma}$ alta freqüência de resistência a macrolídeos e à tetraciclina foi descrita ao se analisar amostras de $S$. suis isoladas na Dinamarca. ${ }^{7}$ Morvan ${ }^{10}$ detectou uma alta resistência de amostras de $S$. suis à tetraciclina e lincomicina na França. Alguns autores acreditam que a resistência aos antimicrobianos encontrada em isolados de $S$. suis pode estar localizada no cromossomo ou no plasmídeo, sendo freqüentemente associada com elementos conjugativos. ${ }^{11}$

A susceptibilidade antimicrobiana pode ser avaliada pela determinação da concentração inibitória mínima (CIM). Um grande número de trabalhos vêm utilizando a técnica da diluição em placas para essa determinação, que apresenta a vantagem de possuir um detalhamento técnico bem definido e fornecimento de dados quantitativos. $^{12}$

Este trabalho teve por objetivo determinar a concentração inibitória mínima de 75 isolados de S. suis previamente sorotipificados, frente a oito antimicrobianos.

\section{Material e Método}

\section{Isolados bacterianos}

Setenta e cinco isolados de S. suis foram obtidos a partir de "swabs" de amostras de cérebro, pulmão, líquido cefalorraquidiano, articulações, sangue, miocárdio e líquido ascítico de suínos com sintomatologia clínica de meningo-encefalite, originados da região Nordeste, CentroOeste, Sul e Sudeste do Brasil. As amostras foram identificadas pelo método da hemólise em ágar sangue de carneiro a 5\%, morfologia pelo Gram e provas bioquímicas de amilase, acetoína, catalase e crescimento em $\mathrm{NaCl}$ a 6,5\% conforme recomendações de Costa ${ }^{13}$. Após o isolamento e confirmação da pureza dos isolados, $1 \mathrm{ml}$ dos mesmos foram estocados em caldo Tryptic soy (TSB-Merk, Darmstad, West Germany) com $10 \%$ de glicerol a $-80^{\circ} \mathrm{C}$. Os isolados foram subcultivados por duas vezes, sendo o primeiro em caldo Tryptic soy (TSB-Merk, Darmstad, West Germany) e posteriormente em ágar Mueller Hinton (Difco, Detroit, EUA) suplementado com $5 \%$ de sangue de carneiro. Os cultivos foram realizados a $37^{\circ} \mathrm{C} \mathrm{em}$ microaerofilia por 18 a 24 horas.

\section{Sorotipificação dos isolados}

Foram utilizados isolados de S. suis previamente sorotipificados por Costa ${ }^{13}$. Dos 75 isolados de $S$. suis testados, $2(2,6 \%)$ foram do sorotipo $1,32(42,7 \%)$ do sorotipo 2, $1(1,3 \%)$ do sorotipo $3,1(1,3 \%)$ do sorotipo $8,4(5,4 \%)$ do sorotipo $9,2(2,6 \%)$ do sorotipo $11,11(14,7 \%)$ do sorotipo 14 , $14(18,7 \%)$ dos sorotipos $1 / 7 / 14$ e $8(10,7 \%)$ isolados não foram sorotipificados.

\section{Concentração Inibitória Mínima (CIM)}

Preparação das placas com antibióticos - Para a preparação das placas foi utilizado ágar Mueller Hinton (Difco, Detroit, EUA) previamente esterilizado em frascos individuais. Após esterilização o meio foi suplementado com $5 \%$ de sangue de carneiro, adicionado com os antibióticos nas concentrações desejadas e colocado em placas de Petri de $100 \mathrm{~mm}$ de diâmetro. Volumes apropriados de soluções estoque de cada um dos antimicrobianos nas concentrações iniciais de $10.000 \mathrm{mg} / 1,1.000$ $\mathrm{mg} / \mathrm{l}$ e $100 \mathrm{mg} / \mathrm{l}$ foram diluídos para se 
obter concentrações variando de 0,25 a 256 $\mu \mathrm{g} / \mathrm{ml}$. Foram feitas duas placas com cada concentração antibiótica, as quais foram confeccionadas 18 horas antes da realização dos ensaios e mantidas em estufa a $37^{\circ} \mathrm{C}$ para avaliação da esterilidade. As seguintes bases farmacológicas foram empregadas: ampicilina, amoxicilina, ceftiofur sódico, florfenicol, lincomicina, penicilina, sulfametoxazol + trimetoprim e tetraciclina. As mesmas foram adquiridas de indústrias farmacêuticas no seu estado puro.

Inóculo e CIM - De cada isolado, retirou-se três a cinco colônias de $S$. suis, removidas de culturas com 18 horas de crescimento em ágar Mueller Hinton (Difco, Detroit, EUA), suplementado com 5\% de sangue de carneiro. As colônias foram suspendidas em $2 \mathrm{ml}$ de salina estéril a $0,85 \%$ até atingir turbidez equivalente ao tubo 0,5 da escala de McFarland, contendo aproximadamente $1,5 \times 10^{8} \mathrm{ufc} / \mathrm{ml}$. As placas foram inoculadas com $1 \mu \mathrm{lda}$ suspensão bacteriana utilizando o replicador de Steer $^{14}$, não ultrapassando 30 minutos entre o preparo do inóculo e incubação. As placas foram incubadas por 24 horas a $37^{\circ} \mathrm{C}$ em atmosfera de microaerofilia, segundo metodologia descrita no National Commitee for Clinical Laboratory Standard ${ }^{15}$. Em cada bateria de testes foram incluídas duas placas sem os antimicrobianos com o inóculo bacteriano (controle negativo) e placas inoculadas com as estirpes de referência Pseudomonas aeruginosa ATCC 27853 e Escherichia coli ATCC 25922 (controles positivos), da American Type Culture Collection (ATCC, Rockville, Maryland, EUA $)^{15}$. A leitura do teste foi realizada após 24 horas de incubação a $37^{\circ} \mathrm{C}$, sendo iniciada pelas placas controle sem os antimicrobianos (controles negativos), e em seguida pelas estirpes de referência da ATCC (controles positivos), comparando-se as CIM obtidas nas amostras controles positivos com as preconizadas pelo National Commitee for Clinical Laboratory Standard ${ }^{15}$. A CIM dos isolados de $S$. suis foi definida como a menor concentração em que não foi observado nenhum crescimento bacteriano visível a olho nú ou quando ocorreu crescimento de somente uma colônia. Em adição, foram determinadas as menores concentrações em $\mu \mathrm{g} / \mathrm{ml}$ capazes de inibirem $50 \%$ e $90 \%$ dos isolados, calculadas pelo (CIM) ${ }_{50}$ e (CIM $)_{90}{ }^{14}$. Todos os ensaios foram feitos em duplicata.

\section{Resultados e Discussão}

Grande número dos estudos relacionados à susceptibilidade antimicrobiana não fazem referência ao sorotipo das amostras de $S$. suis s.17 $^{5,}$. Entretanto, diferenças nos resultados de susceptibilidade podem ser observadas dependendo do sorotipo do isolado. Portanto, torna-se importante correlacionar a susceptibilidade antimicrobiana ao sorotipo de S. suis. Neste estudo, os sorotipos com maior prevalência 2, 14 e 9 apresentaram maior susceptibilidade com maior número de amostras inibidas em menores valores de CIM frente a amoxicilina e florfenicol.

O sorotipo 2 apresentou alto percentual de resistência a maioria dos antimicrobianos testados: ampicilina, ceftiofur sódico, lincomicina, penicilina e tetraciclina com a maioria das amostras apresentando CIM $>32 \mu \mathrm{g} / \mathrm{ml}$. Resultados semelhantes a este foram encontrados por Cantin et al. ${ }^{8}$ que descreveram uma alta freqüência de resistência a macrolídeos e tetraciclina para isolados do sorotipo 2. Os valores da CIM para sulfametoxazoltrimetoprim apresentaram-se distribuídos nas várias concentrações testadas para todos os sorotipos analisados, o que demonstra uma grande variação de susceptibilidade dos sorotipos testados frente a este antimicrobiano. Esses resultados demonstram a existência de resistência entre isolados de um mesmo sorotipo frente a determinado antimicrobiano (Tabela 1). Foram observados alguns intervalos na seqüência de distribuição da CIM dos antimicrobianos estudados (Tabela 1), mostrando à diferença de susceptibilidade dentro de um mesmo sorotipo.

De acordo com os resultados obtidos 
Tabela 1 - Concentração inibitória mínima de oito antimicrobianos contra sorotipos de Streptococcus suis isolados nas regiões Nordeste, Centro-Oeste, Sul e Sudeste do Brasil

\begin{tabular}{|c|c|c|c|c|c|c|c|c|c|c|c|c|c|c|}
\hline \multirow[t]{2}{*}{ Antimicrobiano } & \multirow[t]{2}{*}{ Sorotipo } & \multirow{2}{*}{$\begin{array}{c}\text { № de } \\
\text { isolados }\end{array}$} & \multicolumn{12}{|c|}{ № de isolados com CIM $(\mu \mathrm{g} / \mathrm{ml})$} \\
\hline & & & $\geq 0,25$ & 0,5 & 1 & 2 & 4 & 8 & 16 & 32 & 64 & 128 & 256 & $>256$ \\
\hline \multirow[t]{9}{*}{ Sulfa/ Trimetoprim } & 1 & 2 & & & & & & & $1^{*}$ & & & & & $1^{*}$ \\
\hline & 2 & 32 & & & $2 *$ & 9* & $6^{*}$ & $6^{*}$ & $3^{*}$ & $2^{*}$ & & $2 *$ & & $2^{*}$ \\
\hline & 3 & 1 & & & & $1^{*}$ & & & & & & & & \\
\hline & 8 & 1 & & & & & & $1^{*}$ & & & & & & \\
\hline & 9 & 4 & & & $1^{*}$ & & & & & & $1^{*}$ & & & $2^{*}$ \\
\hline & 11 & 2 & & & & & & & & & & & $1 *$ & $1^{*}$ \\
\hline & 14 & 11 & & & & $6^{*}$ & $2^{*}$ & $1^{*}$ & & & & & & $2^{*}$ \\
\hline & $1 / 7 / 14$ & 14 & & & $2 *$ & $3 *$ & $4^{*}$ & $1^{*}$ & & & $2 *$ & $1 *$ & & $1^{*}$ \\
\hline & $\begin{array}{c}\text { Não } \\
\text { sorotipificado }\end{array}$ & 8 & & & $1^{*}$ & $1^{*}$ & $1^{*}$ & & $3^{*}$ & & & & & $2^{*}$ \\
\hline \multirow[t]{9}{*}{ Tetraciclina } & 1 & 2 & & & & & & & & $2 *$ & & & & \\
\hline & 2 & 32 & & & & & & & & & $3^{*}$ & $29 *$ & & \\
\hline & 3 & 1 & & & & & & & & & & $1^{*}$ & & \\
\hline & 8 & 1 & & & & & & & & & & $1^{*}$ & & \\
\hline & 9 & 4 & & & & & & & & & $3^{*}$ & $1^{*}$ & & \\
\hline & 11 & 2 & & & & & & & & & $1^{*}$ & $1^{*}$ & & \\
\hline & 14 & 11 & & & & & & & $1^{*}$ & & $2 *$ & $8 *$ & & \\
\hline & $1 / 7 / 14$ & 14 & & & $1^{*}$ & & & $1^{*}$ & $1^{*}$ & $2^{*}$ & $2^{*}$ & $7^{*}$ & & \\
\hline & $\begin{array}{c}\text { Não } \\
\text { sorotipificado }\end{array}$ & 8 & $2^{*}$ & $1^{*}$ & & & & & & & $1^{*}$ & $4^{*}$ & & \\
\hline \multirow{9}{*}{ Amoxicilina } & 1 & 2 & $1^{*}$ & & $1 *$ & & & & & & & & & \\
\hline & 2 & 32 & $2^{*}$ & $1^{*}$ & $15^{*}$ & $14^{*}$ & & & & & & & & \\
\hline & 3 & 1 & & $1^{*}$ & & & & & & & & & & \\
\hline & 8 & 1 & & $1^{*}$ & & & & & & & & & & \\
\hline & 9 & 4 & & & & $4^{*}$ & & & & & & & & \\
\hline & 11 & 2 & $1^{*}$ & & $1^{*}$ & & & & & & & & & \\
\hline & 14 & 11 & & $2^{*}$ & $5^{*}$ & $4^{*}$ & & & & & & & & \\
\hline & $1 / 7 / 14$ & 14 & $2^{*}$ & $1^{*}$ & $3 *$ & $3^{*}$ & $5^{*}$ & & & & & & & \\
\hline & $\begin{array}{c}\text { Não } \\
\text { sorotipificado }\end{array}$ & 8 & $2^{*}$ & & $4^{*}$ & $2^{*}$ & & & & & & & & \\
\hline \multirow[t]{9}{*}{ Ampicilina } & 1 & 2 & & & & & & & & & $2^{*}$ & & & \\
\hline & 2 & 32 & & & $1^{*}$ & & & & & $4^{*}$ & $\begin{array}{l}18 \\
*\end{array}$ & $8^{*}$ & $1^{*}$ & \\
\hline & 3 & 1 & & & & & & & & & $1 *$ & & & \\
\hline & 8 & 1 & & & & & & & & & $1^{*}$ & & & \\
\hline & 9 & 4 & & & & & & & & & $4^{*}$ & & & \\
\hline & 11 & 2 & & & & & & & $1^{*}$ & & $1^{*}$ & & & \\
\hline & 14 & 11 & & & & & & $1^{*}$ & & $1^{*}$ & $5^{*}$ & $4 *$ & $1^{*}$ & \\
\hline & $1 / 7 / 14$ & 14 & & $1^{*}$ & & & & & $1^{*}$ & $4^{*}$ & $6^{*}$ & $2^{*}$ & & \\
\hline & $\begin{array}{c}\text { Não } \\
\text { sorotipificado }\end{array}$ & 8 & & $1^{*}$ & & & & & $1^{*}$ & $1^{*}$ & $1^{*}$ & $4^{*}$ & & \\
\hline \multirow[t]{9}{*}{ Ceftiofur sódico } & 1 & 2 & & & & & & & & & & $1 *$ & $1 *$ & \\
\hline & 2 & 32 & & & & & & & & & & $5 *$ & $\begin{array}{l}23 \\
*\end{array}$ & $4 *$ \\
\hline & 3 & 1 & & & & & & & & & & & $1 *$ & \\
\hline & 8 & 1 & & & & & & & & & & & $1 *$ & \\
\hline & 9 & 4 & & & & & & & & & & & $4^{*}$ & \\
\hline & 11 & 2 & & & & & & & & & & & $2 *$ & \\
\hline & 14 & 11 & & & & & & & & & & $4 *$ & $7 *$ & \\
\hline & $1 / 7 / 14$ & 14 & $2 *$ & & & & 1 * & * $1 *$ & & $1 *$ & $2 *$ & $2 *$ & $5^{*}$ & \\
\hline & $\begin{array}{c}\text { Não } \\
\text { sorotipificado }\end{array}$ & 8 & & $1^{*}$ & & & $1 *$ & $*$ & & $1 *$ & & $1 *$ & $4^{*}$ & \\
\hline
\end{tabular}

*número de isolados que tiveram seu cres cimento inibido na respectiva concentração do antibiótico.

com a CIM, a amoxicilina e o florfenicol foram os antimicrobianos frente aos quais os isolados de $S$. suis apresentaram menor resistência, com CIMs menores e um maior número de isolados inibidos nas concentrações de 1 e $2 \mu \mathrm{g} / \mathrm{ml}(74,7 \%)$ e 1 $\mu \mathrm{g} / \mathrm{ml}(62,7 \%)$, respectivamente. A penicilina apresentou valores de CIMs intermediários, com um maior número de isolados inibidos nas concentrações de 16 e $32 \mu \mathrm{g} / \mathrm{ml}(78,7 \%)$. Os antimicrobianos aos quais os microrganimos apresentaram maior 
(conclusão)

\begin{tabular}{|c|c|c|c|c|c|c|c|c|c|c|c|c|c|c|}
\hline \multirow[t]{2}{*}{ Antimicrobiano } & \multirow[t]{2}{*}{ Sorotipo } & \multirow{2}{*}{$\begin{array}{c}\text { № de } \\
\text { isolados }\end{array}$} & \multicolumn{12}{|c|}{ № de isolados com CIM $(\mu \mathrm{g} / \mathrm{ml})$} \\
\hline & & & $\geq 0,25$ & 0,5 & 1 & 2 & 4 & & $8 \quad 16$ & $6 \quad 32$ & 64 & 128 & 256 & $>256$ \\
\hline \multirow[t]{9}{*}{ Florfenicol } & 1 & 2 & & $1^{*}$ & $1^{*}$ & & & & & & & & & \\
\hline & 2 & 32 & & $4^{*}$ & $23^{*}$ & $1^{*}$ & $2^{*}$ & $2^{*}$ & & & & & & \\
\hline & 3 & 1 & & & $1 *$ & & & & & & & & & \\
\hline & 8 & 1 & & & $1^{*}$ & & & & & & & & & \\
\hline & 9 & 4 & & & $4^{*}$ & & & & & & & & & \\
\hline & 11 & 2 & & $1^{*}$ & $1^{*}$ & & & & & & & & & \\
\hline & 14 & 11 & & & $7^{*}$ & $2 *$ & $1^{*}$ & $1^{*}$ & & & & & & \\
\hline & $1 / 7 / 14$ & 14 & $1^{*}$ & $3 *$ & $6^{*}$ & $1^{*}$ & $3^{*}$ & & & & & & & \\
\hline & $\begin{array}{l}\text { Não } \\
\text { sorotipificado }\end{array}$ & 8 & & & $3^{*}$ & $2^{*}$ & $2^{*}$ & $1^{*}$ & & & & & & \\
\hline \multirow[t]{9}{*}{ Lincomicina } & 1 & 2 & & & & & & & & & & & & $2^{*}$ \\
\hline & 2 & 32 & & & & & & & & $3^{*}$ & $1^{*}$ & & & $28^{*}$ \\
\hline & 3 & 1 & & & & & & & & & & & & $1^{*}$ \\
\hline & 8 & 1 & & & & & & & & & & & & $1^{*}$ \\
\hline & 9 & 4 & & & & & & & & & & & & $4^{*}$ \\
\hline & 11 & 2 & & & & & & & & & & & & $2^{*}$ \\
\hline & 14 & 11 & & & & & & & & & & & & $11^{*}$ \\
\hline & $1 / 7 / 14$ & 14 & & & & & & & & $1^{*}$ & & $1^{*}$ & & $12 *$ \\
\hline & $\begin{array}{c}\text { Não } \\
\text { sorotipificado }\end{array}$ & 8 & & & & & & & & $1^{*}$ & & & $1^{*}$ & $6^{*}$ \\
\hline \multirow{9}{*}{ Penicilina } & 1 & 2 & & & & $1^{*}$ & & & $1^{*}$ & & & & & \\
\hline & 2 & 32 & & & $1 *$ & $2 *$ & $1^{*}$ & $1 *$ & $7 *$ & $20 *$ & & & & \\
\hline & 3 & 1 & & & & & & & & $1^{*}$ & & & & \\
\hline & 8 & 1 & & & & & & & & $1^{*}$ & & & & \\
\hline & 9 & 4 & & & & & & & $3 *$ & $1^{*}$ & & & & \\
\hline & 11 & 2 & & & & & & & $1^{*}$ & $1 *$ & & & & \\
\hline & 14 & 11 & & & & $1^{*}$ & $1^{*}$ & & $5^{*}$ & $4^{*}$ & & & & \\
\hline & $1 / 7 / 14$ & 14 & $1^{*}$ & & & $1^{*}$ & & $3^{*}$ & $3^{*}$ & $6^{*}$ & & & & \\
\hline & $\begin{array}{l}\text { Não } \\
\text { sorotipificado }\end{array}$ & 8 & & $1^{*}$ & & $1^{*}$ & $1^{*}$ & & $3 *$ & $2^{*}$ & & & & \\
\hline
\end{tabular}

*número de isolados que tiveram seu crescimento inibido na respectiva concentração do antibiótico.

resistência foram ampicilina, com maior número de isolados inibidos nas concentrações de 64 e $128 \mu \mathrm{g} / \mathrm{ml}(76,0 \%)$; ceftiofur sódico, entre 128 e $256 \mu \mathrm{g} / \mathrm{ml}$ (80,0\%); lincomicina, $>256 \mu \mathrm{g} / \mathrm{ml}(89,3 \%)$ e tetraciclina, entre 64 e $128 \mu \mathrm{g} / \mathrm{ml}(85,3 \%)$.

As CIM $_{50}$ e CIM $_{90}$, que indicam a menor concentração capaz de inibir o crescimento de $50 \%$ e $90 \%$ dos isolados, estão demonstradas na tabela 2. A amoxicilina e o florfenicol foram os antimicrobianos que apresentaram a maior atividade inibitória, com CIM inibindo 90\% dos isolados de $S$. suis (CIM) ${ }_{00}$ em menores concentrações que variaram entre $\geq 0,25$ $\leq 2$ e $\geq 0,25-\leq 4 \mu \mathrm{g} / \mathrm{ml}$, respectivamente. A lincomicina e o ceftiofur sódico foram os antimicrobianos menos ativos, necessitando de altas concentrações para inibirem os isolados de $S$. suis, que variaram entre $\geq 32$ $>256$; e $\geq 0,25 \quad-\quad \leq 256 \mu \mathrm{g} / \mathrm{ml}$, respectivamente. A alta proporção de isolados de $S$. suis susceptíveis a antimicrobianos $\beta$ lactâmicos (amoxicilina e

Tabela 2 - Concentração inibitória mínima- $\mathrm{CIM}_{50}$ e concentração inibitória mínima-CIM $\mathrm{M}_{90}$ de oito antimicrobianos frente a isolados de Streptococcus suis isolados nas regiões Nordeste, Centro-oeste, Sul e Sudeste do Brasil

\begin{tabular}{ccc}
\hline Antimicrobianos & $\mathbf{C I M}_{\mathbf{5 0}}(\boldsymbol{\mu \mathrm { g }} / \mathbf{m l})$ & $(\mathbf{C I M})_{\mathbf{9}}(\boldsymbol{\mu} \mathbf{g} / \mathbf{m l})$ \\
\hline Amoxicilina & $\geq 0,25-\leq 1$ & $\geq 0,25-\leq 2$ \\
Ampicilina & $\geq 0,5-\leq 64$ & $\geq 0,5-\leq 128$ \\
Ceftiofur sódico & $\geq 0,25-\leq 256$ & $\geq 0,25-\leq 256$ \\
Florfenicol & $\geq 0,25-\leq 1$ & $\geq 0,25-\leq 4$ \\
Lincomicina & $\geq 32->256$ & $\geq 32->256$ \\
Penicilina & $\geq 02,5-\leq 16$ & $\geq 0,25-\leq 32$ \\
Sulfametoxazol/trimetoprim & $\geq 1,0-\leq 4$ & $\geq 1,0->256$ \\
Tetraciclina & $\geq 0,25-\leq 128$ & $\geq 0,25-\leq 128$ \\
\hline
\end{tabular}


penicilina) está de acordo com outros experimentos realizados por outros pesquisadores. ${ }^{5,7,18}$

Uma maior freqüência de resistência dos isolados ao ceftiofur sódico, lincomicina e tetraciclina corroboram com estudos prévios realizados por outros autores ${ }^{10,18,19}$. Reams et al. ${ }^{20}$ observaram que $81 \%$ das amostras de $S$. suis eram resistentes à tetraciclina. Morvan ${ }^{10}$, na França, descreveu uma susceptibilidade de $38 \%$ e $18 \%$ ao testar amostras de $S$. suis frente a lincomicina e tetraciclina, respectivamente. Na Dinamarca, $20 \%$ das amostras de S. suis isoladas no período de 1995 a 1997 foram resistentes a lincomicina e $44 \%$ a tetraciclina ${ }^{7}$. No Brasil, Pinto et al. ${ }^{21}$, também utilizando 75 isolados de S. suis, observaram um alto percentual de resistência a tetraciclina, lincomicina, sulfametoxazol-trimetoprim e penicilina. A resistência observada para a ampicilina, ceftiofur sódico, lincomicina e tetraciclina pode estar relacionada à maior utilização desses antimicrobianos no controle de $S$. suis nas granjas. Entretanto, Aarestrup et al. ${ }^{7}$ ao analisarem 67 isolados de $S$. suis observaram que todos os isolados apresentaram altos níveis de susceptibilidade a ampicilina e ceftiofur sódico. A diferença na porcentagem de isolados susceptíveis aos antimicrobianos encontrada neste trabalho quando comparados aos valores encontrados por outros autores, pode estar relacionada à variação na concentração das drogas empregadas nas criações ou aos sorotipos de diferentes regiões.

As estirpes de referência utilizadas como controles positivos, Psendomonas aeruginosa ATCC 27853 e Escherichia coli ATCC 25922, mostraram uma variação da CIM, dentro dos valores estabelecidos pelo National Commitee for Clinical Laboratory Standard ${ }^{15}$ para os antimicrobianos testados.

\section{Conclusão}

Os resultados deste estudo demonstram que amoxicilina e florfenicol são os antibióticos de escolha para o tratamento de infecções pelo S. suis. A indicação terapêutica dos antimicrobianos deve levar em consideração os valores obtidos pelas CIMs e as propriedades farmacocinéticas dos antimicrobianos para a sua utilização racional e obtenção dos resultados esperados.

\section{Mininum inhibitory concentration of eigth antibiotics toward isolates of Streptococcus suis}

\begin{abstract}
The minimun inhibitory concentration (MIC) was determined toward amoxicilin, ampicilin, penicillin, ceftiofur, florfenicol, lincomycin, trimethoprim-sulfadiazine and tetracycline for 75 strains of Streptococcus suis. The MIC was performed on sheep blood agar plates containing concentrations varying from 0,25 to $256 \mu \mathrm{g} / \mathrm{ml}$ of the antibiotic described above. The amoxicilin in the concentrations of 1 and $2 \mu \mathrm{g} / \mathrm{ml}$, florfenicol in the concentration of $1 \mu \mathrm{g} / \mathrm{ml}$ and trimethoprim-sulfadiazine in the concentrations of 2 e $8 \mu \mathrm{g} / \mathrm{ml}$, were the antibiotics that presented minor resistance. In contrast, the ampicilin, tetracycline, ceftiofur and lincomycin, presented MIC of 64 and $128 \mu \mathrm{g} / \mathrm{ml}, 64$ and $128 \mu \mathrm{g} / \mathrm{ml}, 128$ and $256 \mu \mathrm{g} / \mathrm{ml}$ and $>256$ $\mu \mathrm{g} / \mathrm{ml}$, respectively. The results of this study show that the amoxicilin and florfenicol are the antibiotics of choice for the treatment of diseases by $S$. suis in swine.
\end{abstract}

Key words:

Streptococcus suis. Microbial sensitivity tests. Antibiotic. Swine. 


\section{Referências}

1 HIGGINS, R.; GOTTSCHALK, M. Streptococcal disease. In: STRAW, B. E.; D'ALLAIRE, S.; MENGELING, W. L.; TAYLOR, D. J. Disease of swine. Ames: lowa State University Press, 1999. p. 563-570.

2 SANFORD, S. E.; HIGGINS, R. Streptococcal disease. In: LEMAN, A. D. Disease of swine. Ames: lowa, State University Press, 1992. p. 588-598.

3 GOTTSCHALK, M. et al. Susceptibility of Streptococcus suis to penicilin. Journal of Veterinary Diagnostic Investigations, v. 3, p. 170-172, 1991.

4 SOBESTIANSKY, J. et al. Meningite estreptocócica. In: SOBESTIANSKY, J. Clínica e patologia suína. 2 ed. Goiânia: O autor, 1999. Impressos especiais.

5 MARTEL, A. et al. Prevalence and mechanism of resistence against macrolides, and lincosamides in Streptococcus suis isolates. Veterinary Microbiology, v. 83, p. $287-297,2001$.

6 STAATS, J. J. et al. Streptococcus suis: past and present. Veterinary Research Communications, v. 21, p. 381 407, 1997.

7 AARESTRUP, F. M. et al. Trends in resistence to antimicrobial agents of Streptococcus suis isolates from Denmark and Sweden. Veterinary Microbiology, v. 63, p. $71-80,1998$.

8 CANTIN, M. et al. Antimicrobial resistance patterns and plasmid profiles of Streptococcus suis isolates. Journal of Veterinary Diagnostic Investigations, v. 4, p. 170-174, 1992.

9 TARRADAS, M. C. et al. Susceptibility of Streptococcus suis to various antimicrobial agents. Journal of Veterinary Medicine B, v. 41, p. 685-688, 1994.

10 MORVAN, H. Sensibilité aux antibiotiques en élevage industriel. In: ANTIMICROBIALS IN ANIMAL INTENSIVE PRODUCTION, EUROPEAN SYMPOSIUM, 1994, France. Proceedings... p. 209222.

11 VIJAYAKUMAR, M. N. et al. Cloning and physical characterization of chromosomal conjugative elements in streptococci. Journal of Bacteriology, v. 166, p. 972977, 1986.
12 NATIONAL COMMITEE FOR CLINICAL LABORATORY STANDARD. Methods for dilution antimicrobial susceptibility test for bacteria that grow aerobically: approved standard. Vollanova, PA, 1997. (NCCLS document. M7-A4).

13 COSTA, A. T. R. Sorotipificação e avaliação da patogenicidade de amostras de Streptococcus suis isoladas de suínos. 2000. 29 f. Dissertação (Mestrado) - Escola de Veterinária, Universidade Federal de Minas Gerais, Belo Horizonte, 2000.

14 WASTESON, Y.; HOIE, S.; ROBERTS, M. C. Characterization of antibiotic resistance in Streptococcus suis. Veterinary Microbiology, v. 41, p. 41-49, 1994.

15 NATIONAL COMMITEE FOR CLINICAL LABORATORY STANDARD. Performance Standards for antimicrobial disk and dilution susceptibility test for bacteria isolated from animals: approved standard. Wayne, EUA, 2002. (NCCLS document. M31-A2).

16 SALMON, S. A. et al. Comparison of MICs of ceftiofur and other antimicrobial agents against bacterial pathogens of swine from the United States, Canada, and Denmark. Journal of Clinical Microbiology, v. 33, p. 2435-2444, 1995.

17 PRIETO, C. et al. Biochemical traits and antimicrobial susceptibility of Streptococcus suis isolated from slaughtered pigs. Journal of Veterinary Medicine B, v. 41, p. 608-617, 1994.

18 MARIE, J. et al. Antimicrobial susceptibility of Streptococcus suis isolated from swine in France and from humans in different countries betweenn 1996 and 2000. Journal of Antimicrobiology Chemotherapy, v. 50, p. 201-209, 2002.

19 VELA, A. I. et al. Antimicrobial susceptibility of clinical strains of Streptococcus suis isolated from pigs in Spain. Veterinary Microbiology, v. 105, p. 143-147, 2005.

20 REAMS, R. Y. et al. Streptococcus suis infection in swine: a retrospective study of 256 cases. Part I. Epidemiologic factors and antibiotic susceptibility patterns. Journal of Veterinary Diagnostic Investigation, v. 5, p. 363-367, 1993.

21 PINTO, F. F. et al. Sensibilidade antimicrobiana de amostras de Streptococcus suis isoladas de suínos com suspeita clínica de meningoencefalite. Revista Brasileira de Medicina Veterinária, v. 25, p. 25-27, 2003. 